\title{
Disciplina y control de los ciudadanos- trabajadores en la era neoliberal
}

\section{Discipline and control of the citizens-laborers in the neoliberal era}

\author{
WACQUANT, LOÏC (2OIO), CASTIGAR A LOS POBRES: EL GOBIERNO NEOLIBERAL \\ DE LA INSEGURIDAD SOCIAL, GEDISA, BARCELONA, ISBN: 978-849-784- \\ I $55-9,446$ PP.
}

El sociólogo Loïc Wacquant plantea que el Estado neoliberal emplea tres grandes estrategias para tratar la marginalidad y la pobreza. La primera consiste en socializar el desempleo y subempleo mediante políticas asistencialistas que apuntan a reducir la visibilidad de las diferencias de clases. Se trata esencialmente de políticas sociales de corte higienista que buscan embellecer el paisaje urbano limpiando la obscenidad de una pobreza áspera y provocadora. Medicalizar a los pobres es la segunda estrategia. Así, se considera a las poblaciones vulnerables de las urbes como enfermos activos o potenciales: alcohólicos, drogadictos, depresivos o locos, pero también poblaciones más susceptibles de sufrir patologías crónicas e infecciosas: VIHsida, obesidad, diabetes, etc. La tercera vertiente del Estado contemporáneo para combatir la pobreza es la penalización. El proceso de normalización de las conductas conlleva la promulgación de decretos que tipifican y penalizan los hábitos de los que menos recursos económicos tienen: "La penalización funciona como una técnica para la invisibilización de los 'problemas' sociales que el Estado, como palanca burocrática de la voluntad colectiva, ya no puede o no quiere tratar desde sus causas, y la cárcel actúa como un contenedor judicial donde se arrojan los desechos humanos de la sociedad de mercado" (p. 25). A estas tres grandes estrategias se debe agregar la política neoliberal que promueve la responsabilidad individual y la sumisión al libre mercado. Wacquant menciona que el Estado desarrolla una serie de estrategias represivas a partir de la construcción ad hoc de representaciones falseadas de la inseguridad pública, por lo que este último se enfoca en: atacar las incivilidades -es decir, las premisas individuales del desorden que rompen con la moral-, aumentar el número de leyes y reglamentos, estigmatizar categorías de la población, consolidar la vigilancia y acción policiaca, castigar con severidad y perdonar nada y a nadie.

Ahora bien, el pensador europeo no concibe una voluntad única, consciente y omnipotente detrás de estas políticas represivas, que sería 
como una intencionalidad maquiavélica libre de actuar. Al respecto Wacquant escribe:

\begin{abstract}
rechazo enérgicamente la opinión conspirativa de la historia que atribuía el desarrollo del aparato punitivo en las sociedades avanzadas a un plan deliberado ejecutado por dirigentes omniscientes y omnipotentes, sean políticos, empresarios o la diversa gama de personas que se benefician del mayor despliegue e intensidad del castigo y de los programas de supervisión destinados a los derechos urbanos propios de la desregulación (p. 26).
\end{abstract}

El autor de Castigar a los pobres opina que esta situación contemporánea de liberación del ciudadano-trabajador de sus antiguas garantías y el concomitante encierro de los marginados, es producto de una batería de iniciativas políticas y consensos construidos en torno a cierto tipo de inseguridad. Wacquant plantea que esos procesos supraindividuales e incluso supracolectivos se articulan sobre la base de una filosofía política acéfala de tratamiento de las clases bajas, cuyos enunciados se vienen difundiendo de manera subliminal en las élites. La tesis de este libro, escribe Wacquant, "es que Estados Unidos está abriendo camino hacia una nueva clase de Estado híbrido, diferente del Estado 'protector', en el sentido que se da a ese término en el Viejo Mundo, y del Estado 'minimalista' y no intervencionista que se atiene al discurso ideológico que le cuentan los defensores del mercado" (p. 81).

De hecho, la creciente precarización del empleo está estrechamente relacionada con una mayor represión de los pobres. Asimismo, en 1996 se promulgó la Personal Responsability and Employment Opportunity Act y las represivas leyes Megan. La reducción del mercado de trabajo y el incremento proporcional de la experiencia profesional y nivel de estudio para ocupar los puestos vacantes, la incertidumbre en cuanto al aumento de la duración del tiempo de trabajo semanal, la multiplicación y diversificación de las tareas a realizar, el aumento constante del rendimiento para alcanzar metas siempre más elevadas, la competencia interna como mecanismo de estimulación del personal y la renovación periódica del contrato laboral, son todos elementos anxiógenos que fragilizan al trabajador. En Las fuentes de la vergüenza, Vincent de Gaulejac mostró, de forma pertinente, las causas múltiples de la ansiedad de los trabajadores vulnerables y sus consecuencias en la vida cotidiana. El Estado federal norteamericano y, junto con él, las autoridades políticas de los países occidentales promueven una flexibilización del empleo con el fin de otorgar más facilidades a los empresarios para contratar, explotar y despedir a los trabajadores. Se normaliza el trabajo precario y flexible con el fin de poder usar más libremente a los trabajadores y desecharlos cuando se decida. Es importante mencionar también la moda del outsourcing 
y el auge de las agencias de colocación para el trabajo temporal -por ejemplo, Manpower Inc. es el tercer empleador más grande de Estados Unidos-. Se responsabiliza a cada trabajador de su carrera, de su desempeño, de los puestos que ocupa o pierde: asistimos hoy en día a la glorificación del individualismo meritocrático. Se proporcionan cursos de empleabilidad y talleres de preparación para la vida cotidiana con la doble finalidad, por parte del Estado, de reeducar a los más vulnerables, así como de poder culparlos de su pobreza económica. Al margen de las cifras oficiales del desempleo, están las estimaciones realistas de las personas subempleadas y de las que se dedican al mercado informal. Las necesidades de sobrevivir orillan a jóvenes y adultos a aceptar condiciones deplorables de trabajo, e incluso incursionar en mercados ilegales. En México, en el año 2010 las cifras oficiales arrojaban una tasa de desempleo de $5.6 \%$, y 12.7 millones de personas dedicados al mercado informal (es decir, $25.8 \%$ de la población económicamente activa). En Estados Unidos $40 \%$ del total de trabajadores tienen contratos precarios y 5.8\% de la masa laboral está constituida por indocumentados. Vivir mal es un hecho social ampliamente compartido más allá de las fronteras y las nacionalidades. En el destacado documental Délits flagrants, Depardon filma la confrontación de un juez parisino con un anciano magrebí, humilde y analfabeto, arrestado por el simple hecho de querer sobrevivir apostando con cartas. En Estados Unidos, en Francia y en muchos países más se combate a los perdedores de la economía de mercado: se les encierra.

El profesor de Berkeley estima que el encarcelamiento es una técnica de regulación de la marginalidad: se encierra a quienes no tienen actividad lucrativa o cuya actividad económica es ilegal. "Lejos de mitigarlo, el Estado caritativo norteamericano es el principal responsable de la feminización y la infantilización de la pobreza; activamente perpetúa tanto sus duras realidades como sus persistentes mitos, es decir, tanto los fundamentos materiales en que se erige como las pervertidas representaciones en las que vive" (p. 134). Todo indica que lo punitivo surgió con fuerza a fines de los noventa para acompañar el incremento del trabajo desocializado. Es interesante notar que los criminólogos y expertos en temas de seguridad pública insisten todos en separar las causas sociales de la responsabilidad individual en materia delictiva. Según ellos, el crimen tiene su único responsable: el criminal, sin importar las causas y condiciones estructurales. La gran mayoría de los profesionales del tratamiento institucional de la violencia rechazan atacar las causas genéricas de la delincuencia, como la precariedad del empleo, la disminución de las garantías laborales y sociales, las restricciones en cuanto al acceso a la salud y las discriminaciones educativas. 
El también autor de Las cárceles de la miseria recuerda que en Estados Unidos $90 \%$ de los beneficiarios de la asistencia social son mujeres, mientras 93\% de los reos son varones: "Esto confirma que los 'clientes' principales de la asistencial y de la carcelaria del Estado neoliberal son, esencialmente, los dos géneros de la misma población arrinconada en las fracciones marginalizadas de la clase trabajadora postindustrial" (p. 157). El gobierno norteamericano emprendió un ataque ideológico contra el principio de asistencia pública, pero al mismo tiempo consolidó una estructura de oportunidades cerrada para los menos favorecidos: "La pobreza del Estado social en el marco de la desregulación necesita y exige la grandeza del Estado penal" (p. 49), sentencia Wacquant, quien reconoce que existe un problema sobre lo que es y lo que debe ser la asistencia social. Actualmente, la asistencia social es condicionada por la calidad moral de los beneficiarios. Podemos ilustrar esta situación en el caso de México con el Programa Oportunidades, cuyo objetivo oficial es combatir la pobreza otorgando becas escolares, siempre y cuando las madres de familia y su prole se muestren obedientes, no falten a la escuela, sean puntuales en las reuniones, acepten trabajar gratuitamente para los demás, etcétera.

El sociólogo francés ve en las reformas legislativas estadounidenses de 1996 el paso del welfare al workfare. Es la promoción institucional de la idea de mérito, metas personales y colectivas que alcanzar, así como la filosofía de la competencia moral. El Poder Ejecutivo federal de Estados Unidos se propuso "corregir las conductas supuestamente inadecuadas y aberrantes, que serían la causa principal de la pobreza persistente" (p. 160). El Estado se liberó de sus obligaciones pasadas al separarse de un gran número de familias necesitadas con diferentes tipos de argumentos, donde la falta de méritos es el principal. La estigmatización institucional de las madres solteras, de las madres menores de edad afrodescendientes, limita seriamente su inserción social. Juzgadas como depravadas, inmaduras e irresponsables, las madres solteras son marginadas en una sociedad puritana que intenta mantener los principios de un orden moral. Asimismo, el discípulo de Bourdieu asevera atinadamente que "El tratamiento penal de la pobreza tiene una carga moral positiva, mientras que la cuestión de la asistencia está irremediablemente 'mancillada' por la inmoralidad" (p. 101). De hecho, conservadores y demócratas ven en la asistencia pública una plaga que retrasa la expansión económica y perjudica las finanzas públicas. En este contexto, se alaba la autoayuda y se invocan de manera reiterada las virtudes de la providencia. Con frecuencia políticos y altos funcionarios de la administración pública exaltan el altruismo caritativo que siembra los valores de solidaridad y sacrificio entre los pobres.

Otro elemento que caracteriza la reducción de los apoyos gubernamentales es el churning, es decir, el aumento de la severidad de los requisitos 
para beneficiarse de la ayuda pública, así como el incremento de la complejidad y tardanza de los trámites burocrático-administrativos. Recibir apoyos gubernamentales es haber logrado vencer una desgastante carrera de obstáculos. Aunado a lo anterior, se tiende a disminuir las ayudas e incrementar de manera inversamente proporcional el compromiso de las y los beneficiarios. La noción de corresponsabilidad que ha invadido el léxico de los estadistas y edificadores de programas, se inscribe directamente en el contexto antes descrito. Las y los beneficiarios deben ser merecedores de los apoyos que pretenden recibir, deben de mostrar y demostrar de forma continua que son moralmente irreprochables. Tienen por obligación enseñar que carecen de empleo pero que sí buscan integrarse en un mercado laboral deprimente, deben mostrar que tienen niños menores a su cargo pero, al mismo tiempo, deben emplear un método de contracepción, y también deben certificar que sí pagan sus impuestos y sus facturas cuando aumentan cada vez más los gastos de las familias pobres. Además, existe la imagen, aparentemente contradictoria, de la beneficiaria como ganadora de la infraclase (underclass) por el hecho de recibir apoyos gubernamentales, pero siempre perdedora en la sociedad por su estatus y el color de su piel. Para ser merecedora, la mujer pobre debe emplear correctamente su tiempo realizando todas las tareas que le son encomendadas. Lejos de estar ausente de los programas asistenciales, la filosofía del workfare se expande de manera capilar mediante el trabajo comunitario gratuito, los grupos de autoayuda y las actividades individuales o colectivas poco remuneradas. Predomina el principio de la donación/contradonación. El workfare ataca a los denominados parásitos de la sociedad, pues considera que no son merecedores de la ayuda del Estado. Cabe recordar que el pensador ultraliberal Herbert Spencer planteaba ya, hace un siglo, la eliminación natural de los ociosos, viciosos e inútiles.

Para Wacquant, el laissez-faire (dejar hacer) y el laissez-passer (dejar pasar) son las dos vertientes de las políticas sociales contemporáneas, las cuales explican el descompromiso del Estado en cuanto a educación, salud y bienestar, y su magnanimidad irresponsable en materia de reducción de las garantías sociales y laborales. En su obra, el sociólogo explica detalladamente cómo y por qué el Estado pasó de ser paternalista, protector y caritativo a ser un Estado Centauro represor. Al ultraliberalismo económico corresponde la ultrarrepresión de las incivilidades mediante la máxima de tolerancia cero. En México, la estrategia del Estado pasó de ser un combate de la pobreza a un combate de los pobres. Esta censura oficial de discursos y actividades no adecuadas llegó, en un caso reciente, al encarcelamiento de dos tuiteros veracruzanos por difundir información no verídica sobre el ataque de una escuela por narcotraficantes, y la subsiguiente promulgación, por parte del Poder Ejecutivo estatal, del delito 
de perturbación del orden social. Según Bourdieu y Wacquant, las variantes que pueden encontrarse en cada país y en cada entidad federativa corresponden en realidad a una interpretación tópica de un pensamiento único en materia de seguridad pública; discurso hegemónico basado en afirmaciones que mezclan oraciones seudoacadémicas y creencias populares. Las autobiografías del ex alcalde de Nueva York, Rudolph Giuliani, las obras apologéticas de conocidos zares anticrimen y los manuales de influyentes asesores en materia de seguridad pública son materiales ampliamente difundidos que alimentan ese pensamiento único.

$\mathrm{Al}$ adoptar los principios del Consenso de Washington, Europa emprendió una nueva estrategia punitiva que tiende a criminalizar a todos aquellos que no cumplen con el modelo del ciudadano-trabajador. Las libertades están bajo vigilancia con el espionaje de las zonas sensibles y de sus habitantes. Los cambios a la legislación permitieron un aumento del número de delitos e incluso autorizaron encarcelar a menores infractores a partir de los 13 ańos de edad. Los jóvenes que ni estudian ni trabajan -los denominados ni-nis-, los jóvenes que se reúnen en bandas afuera de sus tristes moradas para hacer de su desamparo el vector de una sociabilidad incierta, esos jóvenes son, de un lado y del otro del Atlántico, blancos predilectos de las políticas judiciales. A partir de estereotipos fenotípicos y socioeconómicos, el Estado construye un mapeo de la inseguridad. Las palabras inventan criminales y circunscriben territorios baldíos de la legalidad. La delincuencia y su combate son hoy en día la materia de seminarios, simposios, diplomados e institutos especializados. La invención de la inseguridad corresponde a la conexa invención de un mercado de la seguridad privada y pública, personal y colectiva. Los buenos ciudadanos deben sentirse siempre amenazados en sus personas y bienes, por lo que son invitados a colaborar con la policía para reforzar la red de vigilancia. En la ciudad de México, por ejemplo, los módulos vecinales de policía fueron rebautizados como red ciudadana con la idea de eufemizar la represión, haciendo del ciudadano un policía diletante y del policía un elemento clave de la vida de barrio. Delatores anónimos y ciudadanos con mentalidad policiaca son bienvenidos, e incluso en ciertas ocasiones, retribuidos por sus servicios. Se ofrecen recompensas y se garantiza el anonimato de los denunciantes. De manera general, tanto en los comités vecinales como en los grupos de autodefensa rural creados por la Secretaría de la Defensa Nacional, el ciudadano es invitado en ser un ejemplo de abnegación y un militante defensor de los principios de libertad y propiedad privada.

En Estados Unidos la guerra contra las drogas se enfoca sobre todo en el arresto y castigo de los dealers de la calle, la gran mayoría de ellos afrodescendientes o latinos, quienes buscan en esta actividad ilícita una inse- 
gura fuente de ingreso. La racialización de los infractores es consecuencia de una racialización institucionalizada de los problemas. En resumen, escribe Wacquant, "el gueto funciona como una prisión etnorracial: encierra a una categoría deshonrada y reduce gravemente las oportunidades de vida de sus miembros en apoyo de la 'monopolización de los bienes simbólicos y materiales o las oportunidades' ejercidas por el grupo dominante que vive en sus alrededores" (p. 293). En las cárceles de Estados Unidos a los delincuentes se les separa, trata y encierra según el color de su piel y la gravedad de su delito. De igual manera, en México los presos son separados en cárceles, pabellones, pisos y celdas según su delito y el color de su piel. Los aparatos policial, judicial y carcelario reproducen día con día toda una serie de distinciones discriminantes de los pobres. Un caso actual es la etnocárcel chihuahuense de Guachochi -ciudad controlada por narcotraficantes mestizos-, en la cual están hacinados casi exclusivamente indígenas tarahumaras.

Ahora bien, se busca convencer al ciudadano de clase media de que el crimen está en sus puertas, de que es susceptible de ser atacado en cualquier momento por malhechores, él y su familia. El Estado represor requiere un control de la información para difundir el mensaje de la inseguridad y anclarlo en las conciencias individuales. Asimismo, programas televisivos exaltan la eficacia policiaca para identificar, perseguir y neutralizar a los seudodelincuentes - mediante su arresto o su homicidio ante las cámaras-. La fuerza de la ley pretende mostrar que todos los delincuentes son cazados implacablemente hasta caer en manos de una policía honrada y todopoderosa. Esta repetida difusión de una representación maniquea del mundo social donde están los malos de un lado y por el otro los buenos (el Estado, la policía y los ciudadanos delatores), refuerza los prejuicios racistas y clasistas. Es menester señalar que los delitos de cuello blanco (desvío de recursos, enriquecimiento ilícito y falsificación de documentos, entre otros) son castigados en muy pocos casos y de serlo, las personas son condenadas a penas leves que cumplen en centros de detención semiabiertos. Esta magnanimidad de la justicia estadounidense resulta obscena cuando se conoce el monto multimillonario de los fraudes bancarios y fiscales que se cometen cada año, fraudes que llegan incluso a provocar estrepitosas bancarrotas de consecuencias mundiales.

En la ciudad de Nueva York la disminución de los índices de criminalidad correspondieron a un aumento de los arrestos de los trabajadores subempleados que sobreviven difícilmente por debajo de la línea de pobreza. El historial común de los enjuiciados es haber padecido fracturas familiares con divorcios o abandono, una escolaridad caótica e interrumpida, haber sido traumatizados por abusos y violencias físicas, así como haber sido víctima de armas de fuego. El auge del gran gobierno carcelario 
fue posible gracias a la privatización del encierro. La deslocalización de las agencias del ministerio público y de las prisiones obedece a una territorialización de la delincuencia. En Estados Unidos existe un mercado interno de intercambio y transferencia de los reclusos. Por otro lado, el hacinamiento provoca una saturación de la administración penitenciaria y un burning out del personal, responsable de errores en 20 a $40 \%$ de los expedientes. Debido a la sobrepoblación carcelaria, varias ciudades de Estados Unidos fletaron barcos penitenciarios e incluso, en un caso sonado, obligaban a los reos a dormir en autobuses debido a la saturación de las celdas. Las prisiones son incubadoras de enfermedades infecciosas, el callejón sin salida de las prostitutas y drogadictos, el refugio de los indigentes y la casa de los locos. La política de vaciamiento de los hospitales psiquiátricos en la década de los ochenta provocó un incremento de la población encarcelada. Arrojados a las calles, los enfermos mentales constituyen desde entonces una amenaza para la paz social. El mismo Estado que los liberó de sus salvaguardias médicas los manda ahora encarcelar con el fin de sanear el paisaje público. Este higienismo punitivo contribuye a mezclar indistintamente personas provenientes de los bajos fondos de la sociedad. Una parte significativa de los reos sufren trastornos mentales pero solamente una irrisoria minoría recibe tratamiento psiquiátrico, con el argumento falaz de que el policía y el celador son eficaces terapeutas en los tiempos neoliberales. Imposibilitados muchos de ellos para ejercer un oficio remunerado, condenados al oprobio de una sociedad capitalista que glorifica a los ganadores y pisotea a los perdedores, los locos encarcelados son víctimas de las peores infamias. Los cuerpos de esos pobres son lacerados sin cesar por tempestades de ignominias aceptadas, si no es que fomentadas por las autoridades penitenciarias. Debemos agregar también el hecho de que los prisioneros estadounidenses son susceptibles de servir de conejillos de indias para experimentos médicos a cambio de una reducción de su condena.

Se ha normalizado la vigilancia posterior a la condena con el fin de que el ex convicto haga muestra de su buena conducta mediante la obediencia, disciplina y sumisión. En el año 2000, 3.84 millones de estadounidenses estaban bajo supervisión de la justicia penal, incluido el total de los reclusos, de quienes estaban en libertad condicional y de los ex convictos a prueba. De hecho, el aparato policial y de justicia posee expedientes penales de más de 30 millones de personas, lo que corresponde a una tercera parte de la población masculina adulta de Estados Uidos. El registro de los infractores de la ley se ha convertido en un gigantesco nicho de mercado en el cual participan, con enormes ganancias, las más grandes empresas de informática: "El crecimiento geométrico de las bases de datos policiales y judiciales forma parte de un movimiento más amplio de extensión y diversificación 
de la vigilancia policial 'encubierta', que se ha vuelto proactiva y difusa con los años, a raíz del número de agentes y agencias involucradas y, con ellos, el número y la diversidad de sus objetivos" (p. 207). El historial de las personas, sus datos antropométricos y biométricos están en posesión no solamente de las agencias federales y estatales de investigación, sino que esta información personal es compartida y vendida a empresas y particulares. Con la finalidad de informar a los ciudadanos-de-bien de la amenaza virtual de los ciudadanos-de-mal, bases de datos pueden ser consultadas por Internet e incluso en ferias, convirtiéndose en una atracción lúdica como cualquier otra. Buscar delincuentes sexuales en su barrio se ha convertido en una actividad rutinaria que convoca el morbo, el repudio y la ira. Los depredadores sexuales, como se llama a todos aquellos que poseen material pornográfico, practican la sodomía, son exhibicionistas, violan y matan a menores, sistemáticamente son repudiados y acosados: "La execración hiperbólica del pedófilo desconocido en la escena pública sirve tanto para purificar simbólicamente a la familia como para reafirmar su posición establecida como refugio contra la inseguridad, incluso cuando la aceleración de las tendencias neoliberales en la cultura y la economía intentan socavarlo" (p. 332), asevera con acierto el autor de Castigar a los pobres. Arrinconados como verdaderos parias sociales, los denominados depredadores sexuales se ven obligados a huir y vivir en la clandestinidad. La histeria social de una sociedad puritana en sus fundamentos y principios, exige de sus chivos expiatorios el pago eterno de sus culpas.

Finalmente, podemos concluir que esta obra sobre el tratamiento institucional de la marginalidad en Estados Unidos contiene una estimulante reflexión para entender el doble proceso de extensión del liberalismo económico y castigo más severo de los pobres. Lejos de circunscribirse a un solo país, esta moda política de corte neoliberal se ha exportado a numerosas naciones, México incluido. De esa forma, las cohortes de perdedores, víctimas de la injusticia económica, son considerados a priori una amenaza para el orden establecido. No es falso afirmar que en la actualidad el Estado libra un implacable combate contra lo incorrecto, un combate contra los pobres.

\section{Bibliografía}

De Gaulejac, Vincent (2008), Las fuentes de la vergüenza, Marmol-Izquierdo Editores, Buenos Aires.

Wacquant, Loïc (2000), Las cárceles de la miseria, Manantial, Buenos Aires. 
Recibida: 20 de febrero del 2012. Aceptada: 21 de febrero de 2012.

BRUno Lutz Universidad Autónoma Metropolitana, Unidad Xochimilco Correo-e: brunolutz01@yahoo.com.mx

Bruno Lutz. Es profesor-investigador titular en la Universidad Autónoma Metropolitana, plantel Xochimilco, y miembro del Sistema Nacional de Investigadores (SNI). Es licenciado en sociología y maestro en antropología por la Universidad París III, y doctor en ciencias sociales por la Universidad Autónoma Metropolitana (UAM). Sus líneas de investigación son: la relación del Estado con los campesinos, las organizaciones rurales, y las formas sociales de dominación. Ha dictado más de veinte conferencias magistrales sobre temas de teoría sociológica y sociología rural. También ha impartido seminarios de posgrado en México y Uruguay; actualmente da clases en el doctorado de ciencias sociales y en la licenciatura en sociología en la UAM. Ha coordinado varios libros, el último: Balance y perspectivas del campo mexicano, a más de una década del TLCAN y el movimiento zapatista, vol. III, Migraciones y movilidad laboral, IIsUNAM-AMER, México (2010). También ha publicado una cuarentena de artículos científicos en revistas nacionales e internacionales, los últimos son: "El rumor del nopal chino en México: construcción institucional y efectos sociales de informaciones tergiversadas", Comunicación y Sociedad, 17, Guadalajara, pp. 179-204 (2012); "El capital social a discusión. Caso del desarrollo rural en México", Pampa, 7 (7), Buenos Aires, pp. 69-93 (2011); "Liberación del labrador y construcción del hombre nuevo en el México rural, 1920-1940", en Les Colloques du Bicentenaire des indépendances d'Amérique Latine, CD-ROM, Cultures France-IHEAL (2011). 